\title{
Microstructural Evaluation of Phase Instability in Large Bandgap Metal Halide Perovskites
}

Dohyung Kim, "I Jihoo Lim, "S Seungmin Lee, "I Arman Mahboubi Soufiani,* Eunyoung Choi, Anton V. Ievlev, Nikolay Borodinov, Yongtao Liu, Olga S. Ovchinnikova, Mahshid Ahmadi, Sean Lim, Pankaj Sharma, Jan Seidel, Jun Hong Noh,* and Jae Sung Yun*

Cite This: https://doi.org/10.1021/acsnano.1c08726

Read Online

ACCESS 1

Lلll Metrics \& More

Article Recommendations

Supporting Information

ABSTRACT: The optoelectronic performance of organic-inorganic halide perovskite (OIHP)-based devices has been improved in recent years. Particularly, solar cells fabricated using mixed-cations and mixed-halides have outperformed their single-cation and single-halide counterparts. Yet, a systematic evaluation of the microstructural behavior of mixed perovskites is missing despite their known composition-dependent photoinstability. Here, we explore microstructural inhomogeneity in $\left(\mathrm{FAPbI}_{3}\right)_{x}\left(\mathrm{MAPbBr}_{3}\right)_{1-x}$ using advanced scanning probe microscopy techniques. Contact potential difference

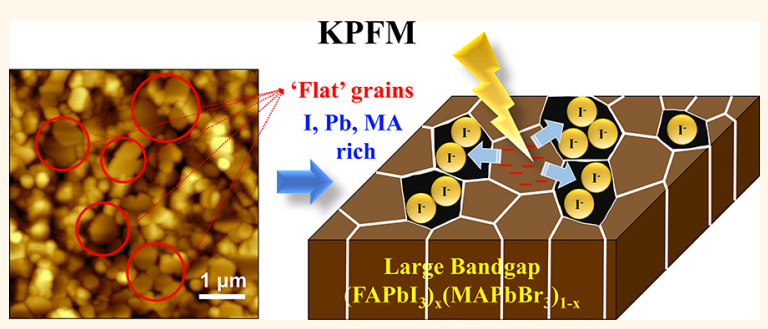
(CPD) maps measured by Kelvin probe force microscopy show an increased fraction of grains exhibiting a low CPD with flat topography as $\mathrm{MAPbBr}_{3}$ concentration is increased. The higher portion of low CPD contributes to asymmetric CPD distribution curves. Chemical analysis reveals these grains being rich in $\mathrm{MA}, \mathrm{Pb}$, and $\mathrm{I}$. The composition-dependent phase segregation upon illumination, reflected on the emergence of a low-energy peak emission in the original photoluminescence spectra, arises from the formation of such grains with flat topology. Bias-dependent piezo-response force microscopy measurements, in these grains, further confirm vigorous ion migration and cause a hysteretic piezo-response. Our results, therefore, provide insights into the microstructural evaluation of phase segregation and ion migration in OIHPs pointing toward process optimization as a mean to further enhance their optoelectronic performance.

KEYWORDS: large bandgap perovskites, contact potential difference, inhomogeneity, phase instability, flat grains, ion migration, defects

\section{INTRODUCTION}

Organic-inorganic halide perovskites (OIHP) have attracted huge attention owing to the demonstration of versatile efficient optoelectronic applications such as solar cells, ${ }^{1}$ photodetectors, $^{2}$ and light-emitting diodes. ${ }^{3}$ The contributing attributes are their tunable bandgap and long charge-carrier diffusion length resulting from absorber layer thickness, high defect tolerance, and strong optical absorption coefficient. ${ }^{4-6}$ As a result, power conversion efficiency (PCE) of singlejunction perovskite-based photovoltaic (PV) devices has risen to a recently confirmed value of $25.5 \%$.

The development of efficient wide-bandgap OIHPs, between 1.7 and $1.8 \mathrm{eV}$, have enabled, through proper current matching, ${ }^{8}$ the fabrication of high-efficiency monolithic tandem cells when deposited on top of narrow bandgap PV materials such as silicon and $\mathrm{CuInGaSe}{ }_{2} \cdot{ }^{9-11}$ The bandgap engineering in OIHPs is typically achieved by substituting bromine $(\mathrm{Br})$ atoms with iodine(I) atoms in iodide-based perovskites where an increase in the $\mathrm{Br}$ content results in enlargement of the bandgap. ${ }^{12,13}$ It has been shown that blending formamidinium lead iodide $\left(\mathrm{FAPbI}_{3}\right)$ with methyl- ammonium lead bromide $\left(\mathrm{MAPbBr}_{3}\right)$ further improved thermal stability and high-quality perovskite film formation and hence, high performances can be achieved. ${ }^{14}$ However, devices fabricated using wide-bandgap perovskites exceeding $1.7 \mathrm{eV}$ suffer from larger open-circuit voltage $\left(V_{\mathrm{OC}}\right)$ deficit than narrower bandgap ones, ${ }^{15}$ in addition to a bigger challenge for practical applications due to phase instability issues, ${ }^{16}$ such spatial segregation of the different halide ions in the perovskite leads to separation between $\mathrm{Br}$ - and I-rich regions. ${ }^{17}$ Hoke and colleagues were the first to report on the reversible photoinduced phase segregation of $\mathrm{MAPb}\left(\mathrm{Br}_{x} \mathrm{I}_{1-x}\right)_{3}$ perovskites, with more than $20 \%$ of bromide content, under 1 sun illumination. ${ }^{18}$ They showed that a low-energy emission peak evolves throughout illumination in the photolumines-

Received: October 3, 2021

Accepted: November 22, 2021 
(a)

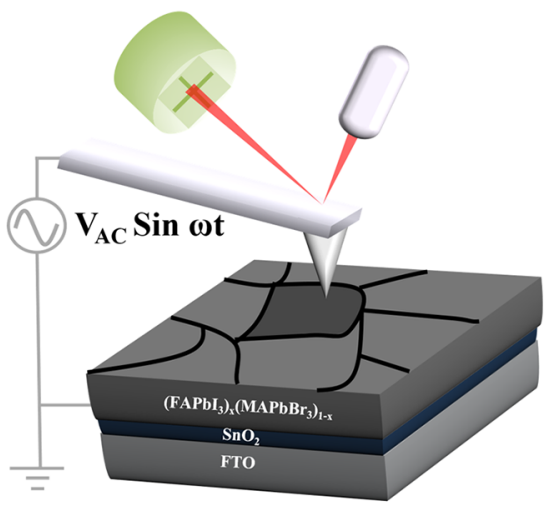

(c)

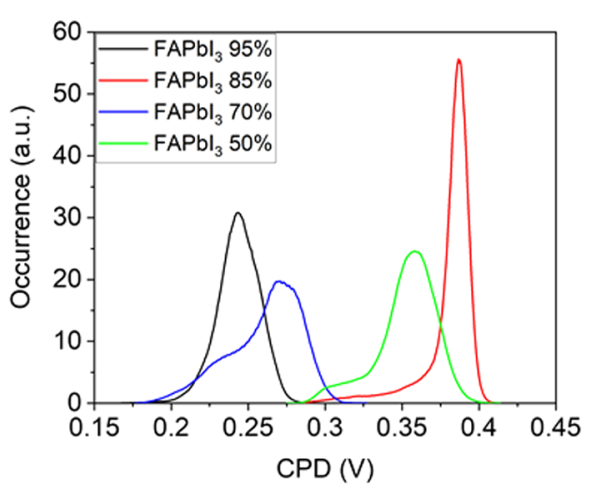

(b)
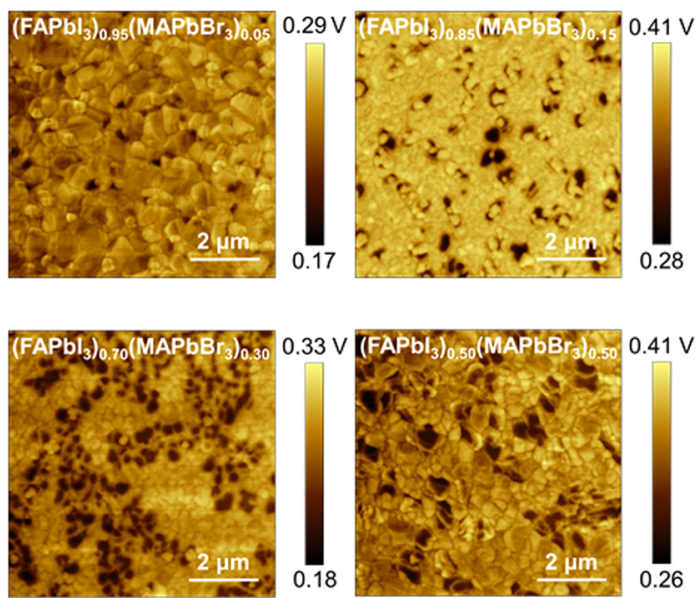

(d)

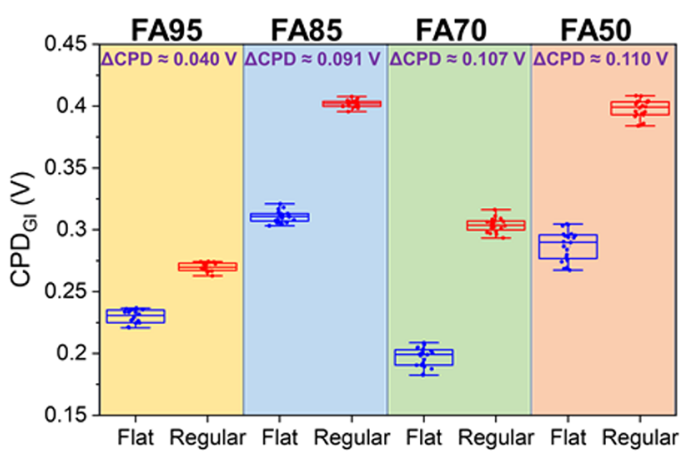

Figure 1. Heterogeneity of mixed halide perovskites with different compositions through KPFM measurements. (a) Schematic illustration of the KPFM measurement setup. (b) CPD spatial maps of $\left(\mathrm{FAPbI}_{3}\right)_{x}\left(\mathrm{MAPbBr}_{3}\right)_{1-x^{*}}$ (c) Histogram of CPD distribution obtained from CPD maps. (d) Box plot of CPD values of flat and regular grains by composition difference.

cence (PL) spectrum while retaining its main high-energy peak with a slight red-shift, as well as the formation of two distinctive X-ray diffraction (XRD) peaks of I- and Br-rich domains (also known as halide segregation). ${ }^{18}$ In this study, a slight red-shift results from phase segregation, for example, Irich minority and Br-rich majority domains which can act as a recombination trap site. Numerous efforts since then have been devoted to overcoming this issue in mixed halide perovskites. First reported by McMeekin et al., mixed halide MA-based perovskites were demonstrated to stabilize by adding in monovalent cations such as formamidinium (FA) and cesium (Cs). ${ }^{19}$ Since then, Cs-containing perovskites have become one of the most popular candidates for large bandgap perovskite fabrication. $^{20,21}$ Even though these mixed perovskites including triple/double cations or anions have shown enhanced efficiencies and improved stability under illumination, $^{22,23}$ they still suffer from microscale inhomogeneity. ${ }^{24,25}$ This microscale heterogeneity has a significant influence on the optoelectronic properties such as the photovoltaic performance $^{26}$ and local charge carrier lifetime. ${ }^{27-29}$ These have been associated with inhomogeneous defect density distribution across the grains, where the defects can act as nonradiative recombination centers. ${ }^{30,31}$

Since the halide segregation in mixed halides- and large bandgap-perovskites has a significant impact on device instability and photovoltaic performance degradation, understanding its root-cause and its subsequent suppression have been extensively studied. Bischak et al. proposed the origin of photoinduced halide segregation to be the localized strain induced by photogenerated charge carriers interacting with the ionic lattice, inducing halide demixing. ${ }^{32}$ Rehman et al. demonstrated that there exists an optimum range for $\mathrm{Cs}$ content in $\mathrm{Cs}_{y} \mathrm{FA}_{1-y} \mathrm{~Pb}\left(\mathrm{Br}_{x} \mathrm{I}_{1-x}\right)_{3}$ perovskite composition outside of which low-crystallinity films are formed that can result in halide segregation by releasing lattice strain between Iand $\mathrm{Br}$-rich domains or providing nucleation sites through defects near grain boundaries (GB). ${ }^{33}$ Furthermore, Zhang et al. suggested that halide segregation can be initiated via the broken ionic bonds of mixed halide perovskites due to the local electric field, caused by photogenerated charge carriers. ${ }^{34}$ Gratia et al. showed interesting results on the nanoscale inhomogeneity of the mixed perovskite, (FAP$\left.\mathrm{bI}_{3}\right)_{0.85}\left(\mathrm{MAPbBr}_{3}\right)_{0.15}$, intrinsically segregated into I-rich domains in its as-fabricated state. ${ }^{35}$

Here, we explore the origin of phase segregation in $\left(\mathrm{FAPbI}_{3}\right)_{x}\left(\mathrm{MAPbBr}_{3}\right)_{1-x}$ through nanoscale microstructural characterizations. Our Kelvin probe force microscopy (KPFM) results in the dark reveal that the area fraction of flat polymorph grains increases when more $\mathrm{MAPbBr}_{3}$ is incorporated into $\mathrm{FAPbI}_{3}$. These so-called flat grains exhibit a different work function by different contact potential difference (CPD). The wavelength dependent KPFM measurements show that the bandgap of flat grains is different as compared to other grains. Also, these flat grains have lower surface photovoltage (SPV) that could be responsible for the $V_{\mathrm{OC}}$ deficit of the large-bandgap OIHPs solar cells. Halide phase segregation within the perovskite films was realized using time-evolved photoluminescence (PL) measurements. In addition, chemical 
imaging measurements including time-of-flight secondary ion mass spectroscopy (ToF-SIMS), atomic force microscopy infrared spectroscopy (AFM-IR), and transmission electron microscopy-energy dispersive X-ray spectroscopy (TEM-EDS) are carried out to correlate microstructural inhomogeneity with different chemical components. Our result reveals that the flat grains are $\mathrm{Pb}, \mathrm{I}$, and $\mathrm{MA}$ rich clusters which exist as defects. The electromechanical responses as a function of bias are explored in these flat grains using the piezo-response force microscopy (PFM) measurement. The PFM results show ferroelectric-like behavior in the flat grains, which is bias sweep rate-dependent, suggesting that ion migration and accumulation significantly occur in the flat grains. Finally, the evolution of CPD spatial variation is investigated before and after illumination. We observe that the flat grains are a source of halide diffusion across the grain boundaries. Our results clearly show that these flat grains are the origin of phase segregation acting as a channel for ion diffusion.

\section{RESULTS AND DISCUSSION}

Figure 1a shows a schematic illustration of the experimental setup for KPFM measurements. The details for sample preparation can be found in the experimental section. All the measurements are performed under ambient conditions with a relative humidity of less than $20 \%$ at room temperature and repetitive results could be obtained within 1 day. The structure of the used samples is FTO/ $\mathrm{SnO}_{2} /\left(\mathrm{FAPbI}_{3}\right)_{x}\left(\mathrm{MAPbBr}_{3}\right)_{1-x}$. The subpanels in Figure $1 \mathrm{~b}$ display CPD spatial maps $(4 \times 4$ $\mu \mathrm{m}^{2}$ ) of four different compositions, (FAP $\left.\mathrm{bI}_{3}\right)_{0.95}\left(\mathrm{MAPbBr}_{3}\right)_{0.05}, \quad\left(\mathrm{FAPbI}_{3}\right)_{0.85}\left(\mathrm{MAPbBr}_{3}\right)_{0.15}$, (FAP$\left.\mathrm{bI}_{3}\right)_{0.70}\left(\mathrm{MAPbBr}_{3}\right)_{0.30}$, and $\left(\mathrm{FAPbI}_{3}\right)_{0.50}\left(\mathrm{MAPbBr}_{3}\right)_{0.50}$ in dark, respectively. The corresponding topographic images can be found in Supporting Information (SI) Figure S1. The measurements were performed in dark to exclude the effect of photogenerated charge carriers at this stage. Note that the wavelength of the laser shone on the cantilever of the AFM is in the infrared range, thus, no absorption is expected to happen within the sample. The CPD values measured in dark represent the work function difference between the tip and the surface of the sample. As can be seen in Figure 1b, a grain-to-grain level inhomogeneity is observed in CPD distribution for all the compositions. We define the grains that correspond to embedded types of grains observed in topographic images for all compositions as "flat" grains and the others as "regular" grains (see SI Figure S2). The CPD maps in Figure $1 \mathrm{~b}$ further indicate that the fraction of flat grains, with lower CPD values, increases as the fraction of $\mathrm{MAPbBr}_{3}$ increases. However, $\left(\mathrm{FAPbI}_{3}\right)_{0.50}\left(\mathrm{MAPbBr}_{3}\right)_{0.50}$ does not follow the trend. The observed flat grains do not increase significantly in $\left(\mathrm{FAPbI}_{3}\right)_{0.50}\left(\mathrm{MAPbBr}_{3}\right)_{0.50}$ perovskite, rather by decreasing the number of the flat grains as compared to (FAP$\left.\mathrm{bI}_{3}\right)_{0.70}\left(\mathrm{MAPbBr}_{3}\right)_{0.30}$ perovskite. The CPD distribution curves shown in Figure 1c have distinctively different CPD peak positions. Symmetric CPD distribution is observed in $\left(\mathrm{FAPbI}_{3}\right)_{0.95}\left(\mathrm{MAPbBr}_{3}\right)_{0.05}$, indicating a relatively homogeneous chemical composition and thus homogeneous electrical properties of the perovskite surface, whereas the other compositions with higher $\mathrm{Br}$ fractions show asymmetric distribution due to the existence of higher fraction of the flat grains, particularly for the $\left(\mathrm{FAPbI}_{3}\right)_{0.70}\left(\mathrm{MAPbBr}_{3}\right)_{0.30}$ film. In addition, Figure $1 \mathrm{~d}$ shows that the CPD differences of grain interior between flat grains and regular grains increases as the bromine content increases. A larger difference $(\sim 120 \mathrm{mV})$ is observed in $\left(\mathrm{FAPbI}_{3}\right)_{0.50}\left(\mathrm{MAPbBr}_{3}\right)_{0.50}$ perovskite than that $(\sim 100 \mathrm{mV})$ in $\left(\mathrm{FAPbI}_{3}\right)_{0.70}\left(\mathrm{MAPbBr}_{3}\right)_{0.30}$ perovskite. This result show that $\left(\mathrm{FAPbI}_{3}\right)_{0.50}\left(\mathrm{MAPbBr}_{3}\right)_{0.50}$ perovskite can lead to the formation of more disordered phases than $\left(\mathrm{FAPbI}_{3}\right)_{0.70}\left(\mathrm{MAPbBr}_{3}\right)_{0.30}$ perovskite. It has been reported that $\mathrm{MA}^{+}$and $\mathrm{FA}^{+}$have different surface energies that influences high crystallinity of the perovskite film and hence inadequate ratio of $\mathrm{MA}^{+}$and $\mathrm{FA}^{+}$favors defect formation on the surface of the film. ${ }^{36}$ Similarly, the inadequate ratio between $\mathrm{MA}$ and FA in this work, especially for higher $\mathrm{MAPbBr}_{3}$ into $\mathrm{FAPbI}_{3}$ perovskite, could have led to grain-tograin scale inhomogeneity in CPD spatial distribution. Furthermore, SI Figure S3 presents PL spectra for four different compositions of $\left(\mathrm{FAPbI}_{3}\right)_{x}\left(\mathrm{MAPbBr}_{3}\right)_{1-x}$ perovskites highlighting the extent of red shifts increases as bromine fraction increases which is the clear evidence of halide phase segregation.

To further characterize the CPD variations on the films during the aging process, we performed KPFM measurements as a function annealing time. As a model system, we selected one mixed perovskite, $\left(\mathrm{FAPbI}_{3}\right)_{0.85}\left(\mathrm{MAPbBr}_{3}\right)_{0.15}$ composition. The result is shown in SI Figure S4. This experimental condition can give thermal stress to the entire film. Mostly, thermal annealing for perovskite fabrication is performed at $100{ }^{\circ} \mathrm{C}$ for $10 \mathrm{~min}$ to minimize the thermal stress. As shown in SI Figure S4a, CPD map reveals uniform distribution in standard annealing condition while flat grains (low CPD regions) are more generated and grown (see SI Figure S4b-d) as thermal stresses increase by longer thermal annealing time. The corresponding topographic images are also displayed in SI Figure S5. These results confirm again that the low CPD regions are consistent with flat grains in topography. When films undergo thermal stresses, the flat grains corresponding low CPD regions gradually increases, which could be a potential reason for film degradation.

To understand the potential influence of the formation of the flat grains, observed CPD maps in the thin films, on the corresponding device performance, perovskite solar cells with these four different compositions were fabricated and their photovoltaic performance was characterized (see current density-voltage $(J-V)$ curves under 1-sun illumination in SI Figure S6). It can be clearly seen that the larger $\mathrm{MAPbBr}_{3}$ fraction exacerbates $J-V$ hysteresis. Also, as the fraction of $\mathrm{MAPbBr}_{3}$ increases the devices' $V_{\mathrm{OC}}$ deficit with respect to its S-Q limit increases (see SI Figure S7), pointing to the potential detrimental impact of a larger share of the flat grains. We emphasize that the flat grains are not the only responsible factor for the measured voltage deficits across various composition since there are other important factors such as interface recombination and contacts/perovskite energy band alignments that greatly impact voltage losses. Nevertheless, the results indicate that the nonradiative recombination-induced voltage loss in $\left(\mathrm{FAPbI}_{3}\right)_{0.95}\left(\mathrm{MAPbBr}_{3}\right)_{0.05}$ devices, which has the smallest portion of the flat grains, is less than in the other compositions, whereas devices with higher $\mathrm{MAPbBr}_{3}$ fractions such as $\left(\mathrm{FAPbI}_{3}\right)_{0.70}\left(\mathrm{MAPbBr}_{3}\right)_{0.30}$ and (FAP$\left.\mathrm{bI}_{3}\right)_{0.50}\left(\mathrm{MAPbBr}_{3}\right)_{0.50}$ encounter severe nonradiative recombination that could be related to the increasing amount of the flat grains.

To gain more insight into the light responsivity of the individual grains, we performed KPFM measurements under illumination using light sources of different wavelengths, 550 and $720 \mathrm{~nm}$, both with an intensity of $200 \mathrm{~mW} / \mathrm{cm}^{2}$. As a 

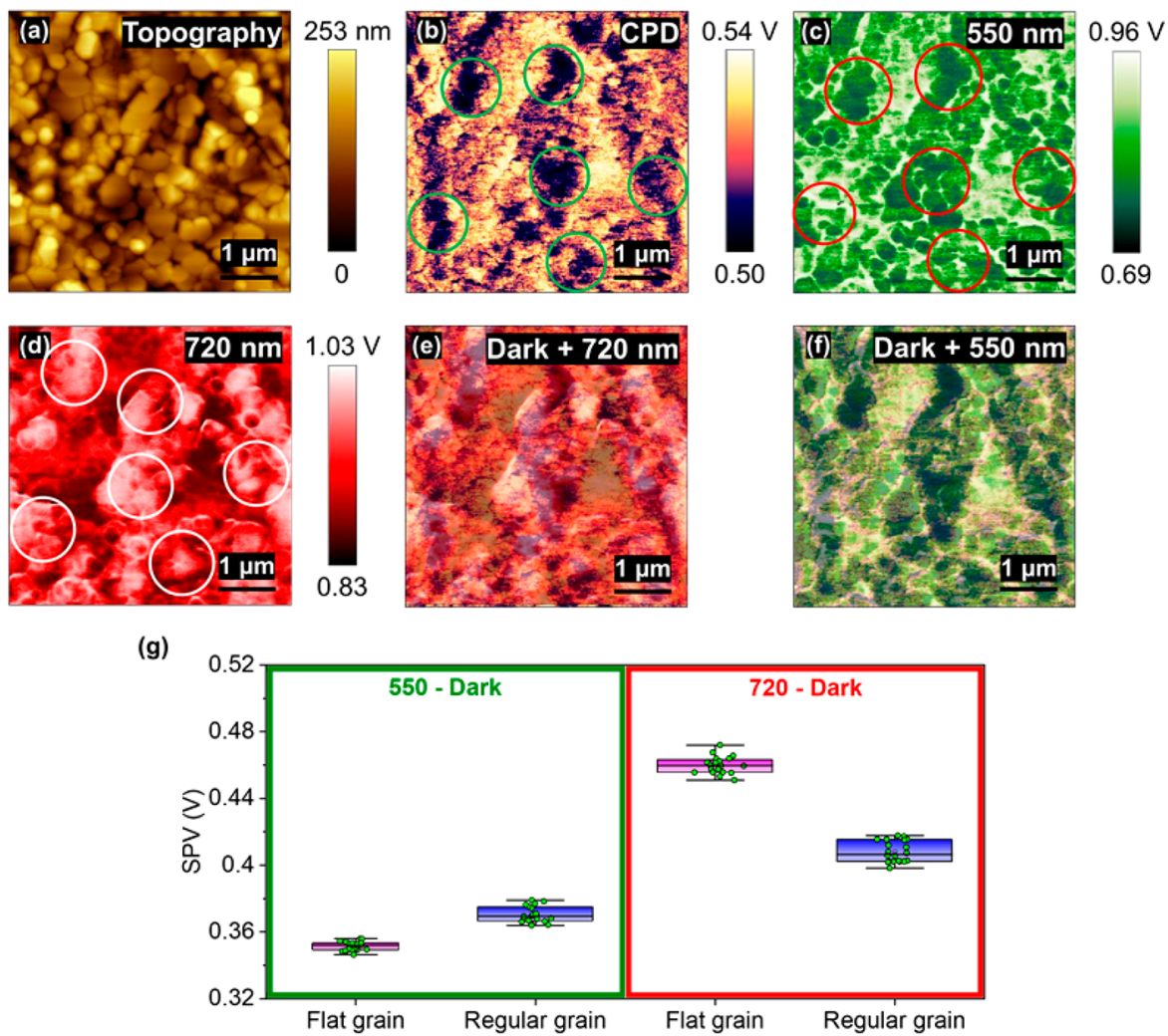

Figure 2. Wavelength-dependent CPD spatial maps. (a) Topographic image of a $\left(\mathrm{FAPbI}_{3}\right)_{0.70}\left(\mathrm{MAPbBr}_{3}\right)_{0.30}$ thin film. CPD spatial maps acquired (b) in the dark and under (c) $550 \mathrm{~nm}$ and (d) $720 \mathrm{~nm}$ laser illumination. (e) Overlaid CPD maps of (e) dark and $720 \mathrm{~nm}$, and (f) dark and $550 \mathrm{~nm}$. (g) SPV difference between flat grains and regular grains in 550 and $720 \mathbf{n m}$.

(a)

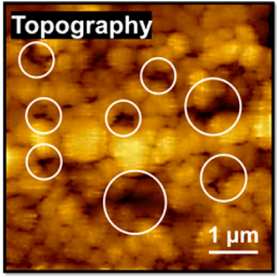

(d)

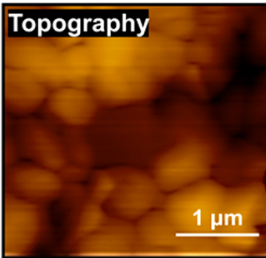

(g)

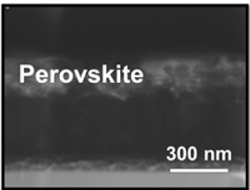

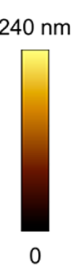

(b)
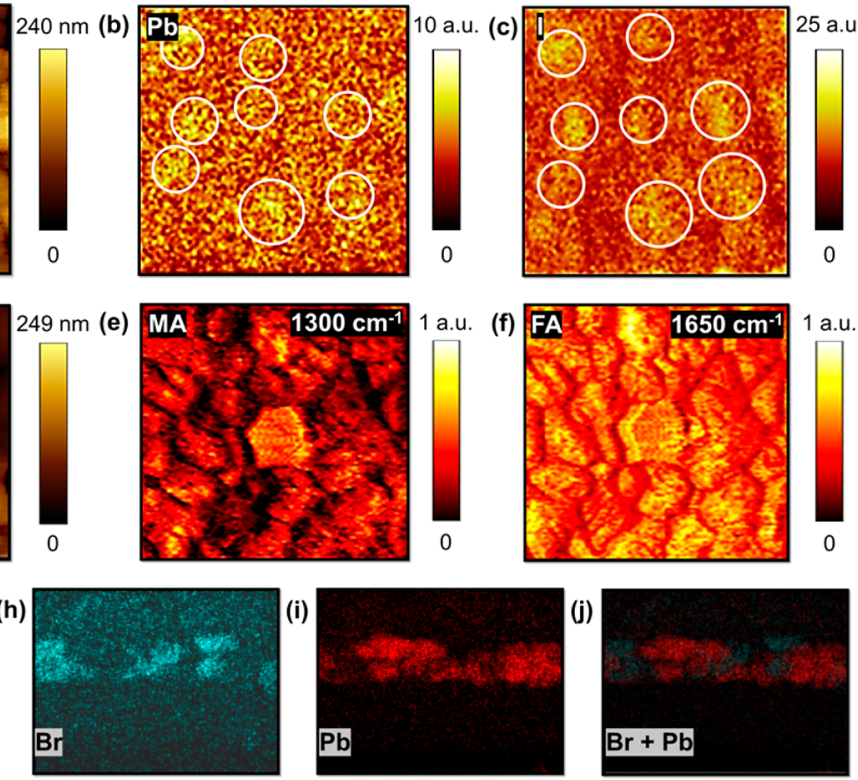

Figure 3. Grain-to-grain chemical composition. (a) AFM topographic map of the $\left(\mathrm{FAPbI}_{3}\right)_{0.70}\left(\mathrm{MAPbBr}_{3}\right)_{0.30}$ perovskite surface. The corresponding chemical maps of $(b) \mathrm{Pb}$ and (c) I component measured via in ToF-SIMS. (d) AFM topographic image of a different region of $\left(\mathrm{FAPbI}_{3}\right)_{0.70}\left(\mathrm{MAPbBr}_{3}\right)_{0.30}$ film. The corresponding chemical maps of $(\mathrm{e}) \mathrm{MA}^{+}$and $(\mathrm{f}) \mathrm{FA}^{+}$via AFM-IR measurements. (g-i) EDS maps of $\mathrm{Br}$ and $\mathrm{Pb}$ components in TEM analysis. ( $\mathrm{j}$ ) The Overlaid EDS map of $\mathrm{Br}$ and $\mathrm{Pb}$.

model system, we selected $\left(\mathrm{FAPbI}_{3}\right)_{0.70}\left(\mathrm{MAPbBr}_{3}\right)_{0.30}$ composition that contains a large number of flat grains. Figure $2 a, b$ show the topographic and CPD images under dark condition, respectively. Illumination wavelength dependent CPD spatial maps at 550 and $720 \mathrm{~nm}$ are provided in Figure $2 \mathrm{c}, \mathrm{d}$, respectively. We chose these two wavelengths to identify grainto-grain variation in terms of potential bandgap and SPV change. Note that the bandgap of I-rich phases, $\mathrm{FAPbI}_{3}$ and $\mathrm{MAPbI}_{3}$ are $\sim 1.52 \mathrm{eV}$ and $\sim 1.59 \mathrm{eV}$, respectively, while for bromide-rich phases, $\mathrm{MAPbBr}_{3}$ and $\mathrm{FAPbBr}_{3}$ are $\sim 2.31 \mathrm{eV}$ and 
$\sim 2.27 \mathrm{eV}$, respectively. ${ }^{37,38}$ Figure 2e displays an overlaid CPD map measured in dark and under $720 \mathrm{~nm}$ laser illumination. Here, we observe that some of the flat grains turn to brighter contrast (higher CPD) compared to the neighboring regular grains. We calculated change in CPD of the flat and regular grains upon illumination, SPV, which infers CPD measured in dark subtracted from CPD measured in light which is summarized in Figure $2 \mathrm{~g}$. It can be seen that the flat grains have higher SPV compared to the regular grains upon $720 \mathrm{~nm}$ illumination. Two mechanisms may explain this observation. First, the flat grains are I-rich, hence they absorb more of the low-energy photons $(720 \mathrm{~nm})$ with larger charge carrier photogeneration in comparison to the bromide rich grains (regular grains). Second, the flat grains have fewer defects, thereby, demonstrating higher SPV. In order to identify which grain has higher recombination activity, we illuminated the sample with a shorter wavelength laser $(550 \mathrm{~nm})$, which can be absorbed by both the $\mathrm{Br}$ and $\mathrm{I}$ rich phases. Figure $2 \mathrm{f}$ displays an overlaid image of the CPD maps measured in the dark and under $550 \mathrm{~nm}$ laser illumination. It is shown that the grain-tograin CPD variation trend somehow follows the one measured in dark, that is, flat grains remain in darker contrast compared to the regular grains and SPV of the flat grains are lower compared to the regular grains as shown in Figure $2 \mathrm{~g}$. These results inspire us to further explore the flat grains with chemical analysis in the following section.

To confirm the composition of the flat grains on the $\left(\mathrm{FAPbI}_{3}\right)_{0.70}\left(\mathrm{MAPbBr}_{3}\right)_{0.30}$ perovskite film surface, we carried out chemical mapping using ToF-SIMS and AFM-IR measurements. The flat grains range from around $300-500 \mathrm{~nm}$ in size. The sensitivity of ToF-SIMS allows the detection of chemical element distribution with a spatial resolution of $\sim 100 \mathrm{~nm}$. We marked the flat grains with white circles in Figure 3a where there are low height features due to the embedded attribute of the flat grains. Since the precursor stoichiometry was correctly prepared for each perovskite composition, we believe that the formation of the flat grains is not responsible for originally excessive cations or other ionic impurities, rather, by chemical segregation during the crystallization process. Figure $3 b, c$ show the corresponding chemical maps for $\mathrm{Pb}$ and I. It can be seen that both $\mathrm{Pb}$ and I distributions are inhomogeneous and show higher contrast around the flat grain regions (marked by circles). We further identified other chemical components using ToF-SIMS mapping (see SI Figure S6). It was observed that the same regions with high levels of $\mathrm{Pb}$ and $\mathrm{I}$, were depleted of organic $\mathrm{MA}^{+}$and $\mathrm{FA}^{+}$cations as well as $\mathrm{Br}^{-}$ions. However, MA ion concentrations ( 5.4 a.u.) are significantly low and closed to noise level as compared to other ions concentrations, at least above 10 a.u., thus it requires a better resolution to correctly detect MA distribution. One possibility might be decomposition of MA ion under vacuum conditions during ToF-SIMS measurements due to their volatility and instability. ${ }^{39-41}$ In addition, the flat grains do not result from simply $\mathrm{PbI}_{2}$ (either MA or FA deficient) as the flat grains in our CPD map (see Figure 2d) under $720 \mathrm{~nm}$ laser $(1.72 \mathrm{eV}$ ) showed more excited state, for example, light absorption. This phenomenon indicates that the bandgap of the flat grains does not agreement with that $(2 \mathrm{eV})$ of $\mathrm{PbI}_{2}$, thus it is expected that the flat grains contain organic cations either MA or FA. Hence, we have further studied molecular dynamics using AFM-IR measurements which can be operated under ambient conditions with a better resolution to detect MA ions. We believe that this measurement cannot cause serious decom- position of organic cations, especially MA, and lead to more reliable results in terms of detecting organic cations. AFM-IR measurements allow us to construct AFM topography and IR response of the sample surface with nanoscale spatial resolution. The results are shown in Figure $3 \mathrm{~d}-\mathrm{f}$. The detection range of our nanoscale AFM-IR was limited to the vibrational modes ranging from 916 to $1864 \mathrm{~cm}^{-1}$. It was reported that the pronounced vibrational mode associated with $\mathrm{C}-\mathrm{N}$ antisymmetric stretching, featured at $1714 \mathrm{~cm}^{-1}$, owing to the incorporation of $F A$ into a triple-cation $\mathrm{Cs}_{0.05} \mathrm{FA}_{0.79} \mathrm{MA}_{0.16} \mathrm{~Pb}\left(\mathrm{I}_{0.83} \mathrm{Br}_{0.17}\right)_{3}$ perovskite film also exists within our detection range. ${ }^{42}$ Note that the most pronounced vibrational mode for $\mathrm{MAPbI}_{3}$ is featured at $3180 \mathrm{~cm}^{-1}(\mathrm{~N}-\mathrm{H}$ stretch). ${ }^{42}$ Spectral analysis of the vibrational modes located in our detection limit, performed using a non-negative matrix factorization (NMF) approach, confirms the presence of two main components on the film surface (see SI Figure S7). NMF method has been previously used for the analysis of complicated mass spectra in OIHPs and the details of the analysis method can be found in the previous studies. ${ }^{43,44}$ The first component is located around $1300 \mathrm{~cm}^{-1}$ which is possibly related to molecular $\mathrm{MA}^{+}$while the second component is associated with molecular $\mathrm{FA}^{+}$at $1650 \mathrm{~cm}^{-1}$. As can be seen in Figure $3 \mathrm{f}$, the FA component has a more uniform spatial distribution within the constant color scale, while the MA component seems to be segregated into the embedded flat grains. Notably, despite being depleted organic cations in ToFSIMS due to possibly limited resolution, AFM-IR results are more reasonable as AFM-IR measurements are more focused on molecule dynamics. To further confirm this observation, we provided amplitude plots between 1300 and $1650 \mathrm{~cm}^{-1}$ (see SI Figure S8). The asymmetric distribution curve (SI Figure S8a) appears at $1300 \mathrm{~cm}^{-1}$ revealing nonuniform chemical distribution of $\mathrm{MA}^{+}$which corresponds to chemical map at $1300 \mathrm{~cm}^{-1}$ (Figure 3e), while relatively smooth curve (SI Figure S8b) is observed at $1650 \mathrm{~cm}^{-1}$, which implies uniform chemical composition, corresponding to chemical map at 1650 $\mathrm{cm}^{-1}$ (Figure $3 \mathrm{f}$ ). The flat grains could be thought of as the hexagonal shape of $\mathrm{PbI}_{2}$ observed by the previous studies. ${ }^{45,46}$ However, the observed flat grain in our study is not a completely hexagonal shape as the flat grains contain MA cations confirmed by AFM-IR analysis. The underlying mechanisms to form $\mathrm{MA}, \mathrm{Pb}$, and I containing flat grains are not yet discovered but they could be related to the colloidal chemistry of the perovskite precursors that ultimately determines the final crystal structures and morphology. ${ }^{47}$ Cross-sectional EDS mapping in TEM measurements was also conducted to assess the elemental distribution as shown in Figure $3 \mathrm{~g}-\mathrm{i}$. Regions indicating high $\mathrm{Pb}$ concentration are around $300-400 \mathrm{~nm}$ in size, consistent with the grain sizes estimated from Figure $3 \mathrm{~d}$, and do not overlap with $\mathrm{Br}$ element distribution. This is in good agreement with the results of ToFSIMS chemical mapping. Based on our results, it is evident that the flat grains are MA segregated as well as rich in both $\mathrm{Pb}$ and I. This elemental analysis seems to agree with the above KPFM results. The flat grains showed a higher CPD response with the $720 \mathrm{~nm}$ illumination, implying an I-rich characteristic. Also, as seen above (Figure $2 \mathrm{~g}, 550 \mathrm{~nm}$ ), some of the flat grains show poor SPV which could be originating from $\mathrm{Pb}$ interstitials that form deep defect states. ${ }^{48} \mathrm{PbI}_{2}$ can also form a flat morphology, resulting in low $\mathrm{CPD}$ regions as excess $\mathrm{Pb}$ and I ions contribute to ionic defects in the grain level. ${ }^{26}$ However, we confirm that the flats grains are not only composed of $\mathrm{PbI}_{2}$ 

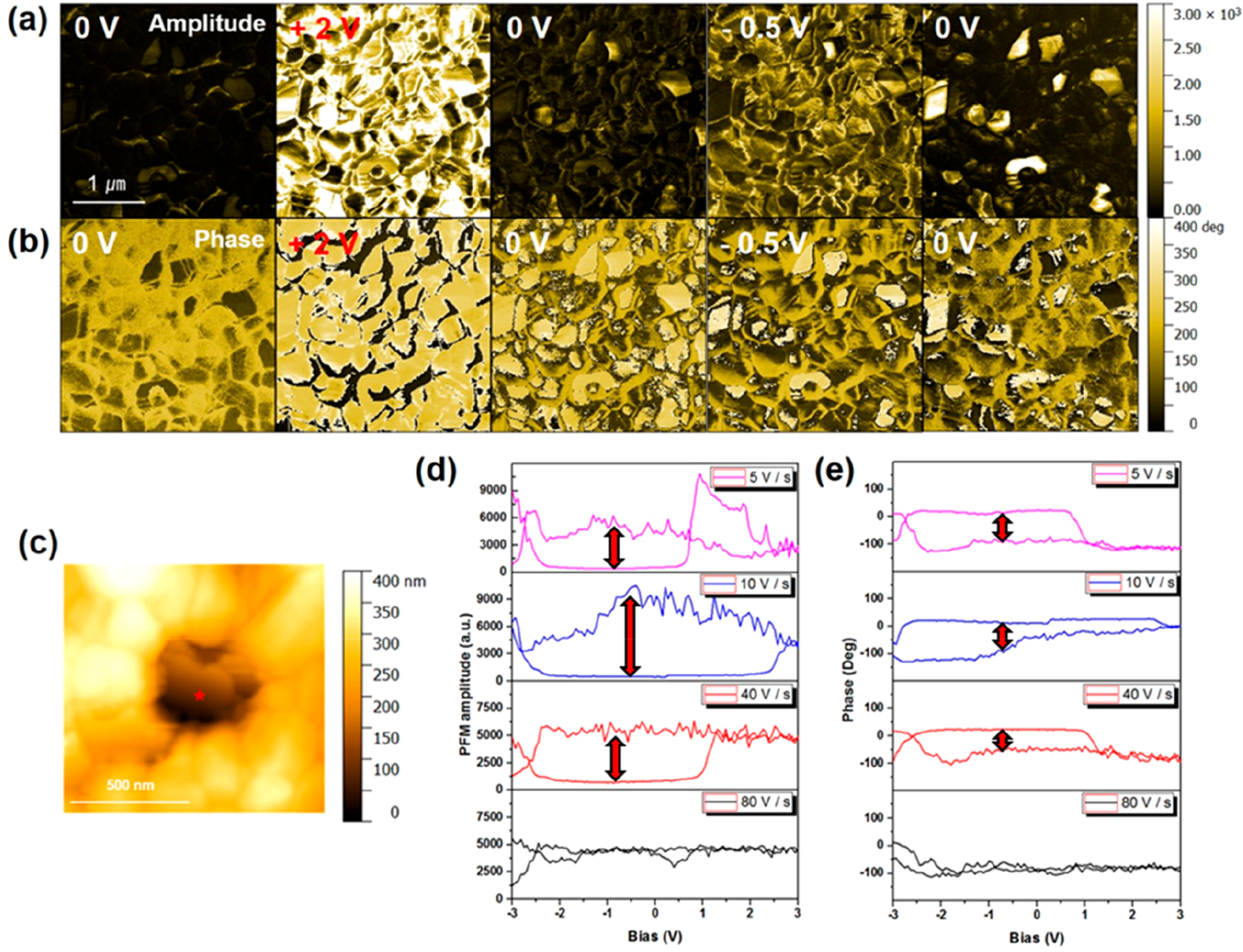

Figure 4. Bias dependent- and sweep rate dependent-PFM response of the perovskite films in the dark. Bias-dependent PFM images of (a) amplitude and $(\mathrm{b})$ phase in the $\left(\mathrm{FAPbI}_{3}\right)_{0.85}\left(\mathrm{MAPbBr}_{3}\right)_{0.15}$ perovskite film. (c) Topography image of the flat grain. The AFM tip is parked at the red star and PFM loops were measured at the corresponding location. Sweep rate dependent-PFM (d) amplitude and (e) phase response.

as our chemical analysis points that the flat grain is rich in $\mathrm{MA}^{+}$ as well.

We then investigated the effect of bias on the evolution of electromechanical responses of the flat grains through biasdependent PFM measurements, performed in the dark. The results are shown in Figure 4. From our previous study, it was realized that local degradation on the film surface occurs at high voltage biases $( \pm 4 \mathrm{~V})$ due to vigorous ion migration, ${ }^{49}$ whereas no degradation happens in $\left(\mathrm{FAPbI}_{3}\right)_{0.85}\left(\mathrm{MAPbBr}_{3}\right)_{0.15}$ perovskite within the bias range of $-0.5 \mathrm{~V}$ to $+2 \mathrm{~V}^{50}$ Therefore, we selected $\left(\mathrm{FAPbI}_{3}\right)_{0.85}\left(\mathrm{MAPbBr}_{3}\right)_{0.15}$ perovskite film and the voltage range -0.5 to $+2 \mathrm{~V}$ to avoid bias-induced damage to the film surface.

Figure $4 \mathrm{a}, \mathrm{b}$ show the amplitude and phase maps with a DC bias voltage, respectively. SI Figure S9 is the corresponding topography image and flat grains are marked by white circles. PFM measurements were performed at around the contact resonance frequency of $200 \mathrm{kHz}$. Note that PFM responses almost disappear when the contact frequency is far away from the center frequency. To optimize PFM response, we applied a modest $\mathrm{AC}$ bias of $2 \mathrm{~V}$. The measurements were carried out consecutively from $0 \mathrm{~V}$ to $+1 \mathrm{~V},+2 \mathrm{~V}, 0 \mathrm{~V},-0.5 \mathrm{~V}$, and then 0 $\mathrm{V}$ again. Interestingly, the observed flat grains reveal flipped behavior in both amplitude and phase responses when bias returns to $0 \mathrm{~V}$. This irreversible PFM response upon application of electrical biases resembles ferroelectric behavior. Several works claimed that there exists ferroelectricity in $\mathrm{MAPbI}_{3}{ }^{51-54}$ while others reported ferroelastic or ferroelectric-like behavior ${ }^{55-57}$ as seen in many other nonferroelectric perovskite oxides. ${ }^{58,59} \mathrm{We}$ previously observed ferroelastic domains in $\left(\mathrm{FAPbI}_{3}\right)_{0.85}\left(\mathrm{MAPbBr}_{3}\right)_{0.15}$ perovskite and also structural variations where the strain was tuned by optical illumination and electrical bias. ${ }^{50}$ The results of Figure 4a-,b suggest that some flat grains exhibit a switching behavior, which could be due to MA segregation, ${ }^{57}$ its free rotation, ${ }^{60}$ or polarity. ${ }^{61}$ To further understand this phenomenon, one flat grain is selected from the topography image Figure 4c corresponding to a dark grain in KPFM images. The sweep rate-dependent piezoresponse-electric bias (P-E) loop measurements were performed in the dark. The results are shown in Figure 4 d,e. For a faster voltage sweep rate, $80 \mathrm{~V} / \mathrm{s}$, the P-E loop has nonferroelectric behavior while a switching behavior appears when the rate reduced to $5 \mathrm{~V} / \mathrm{s}$. The latter is not a completed butterfly shape and thus confirming the absence of an ideal ferroelectric response. Typically, the butterfly like shape in amplitude response as well as phase change by $180^{\circ}$ indicates ferroelectricity. Therefore, rather than ferroelectricity, we suspect that this behavior is in all likelihood associated with both charge and ion trapping in flat grains. ${ }^{62}$ Nonetheless, the ferroelectric characteristic cannot be fully disregarded as the 
(a)

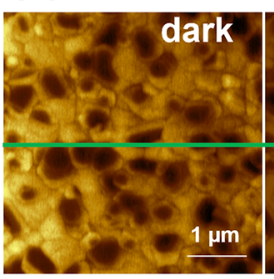

(b)

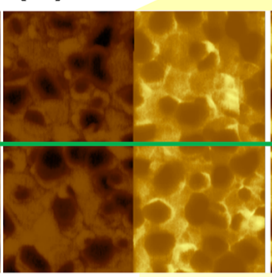

(c)

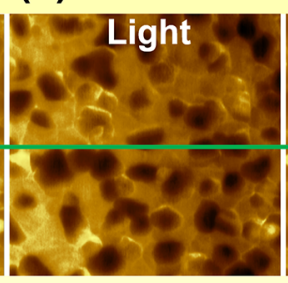

(d)

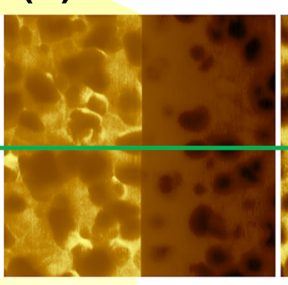

(e)
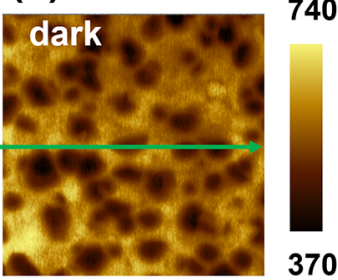

(f)

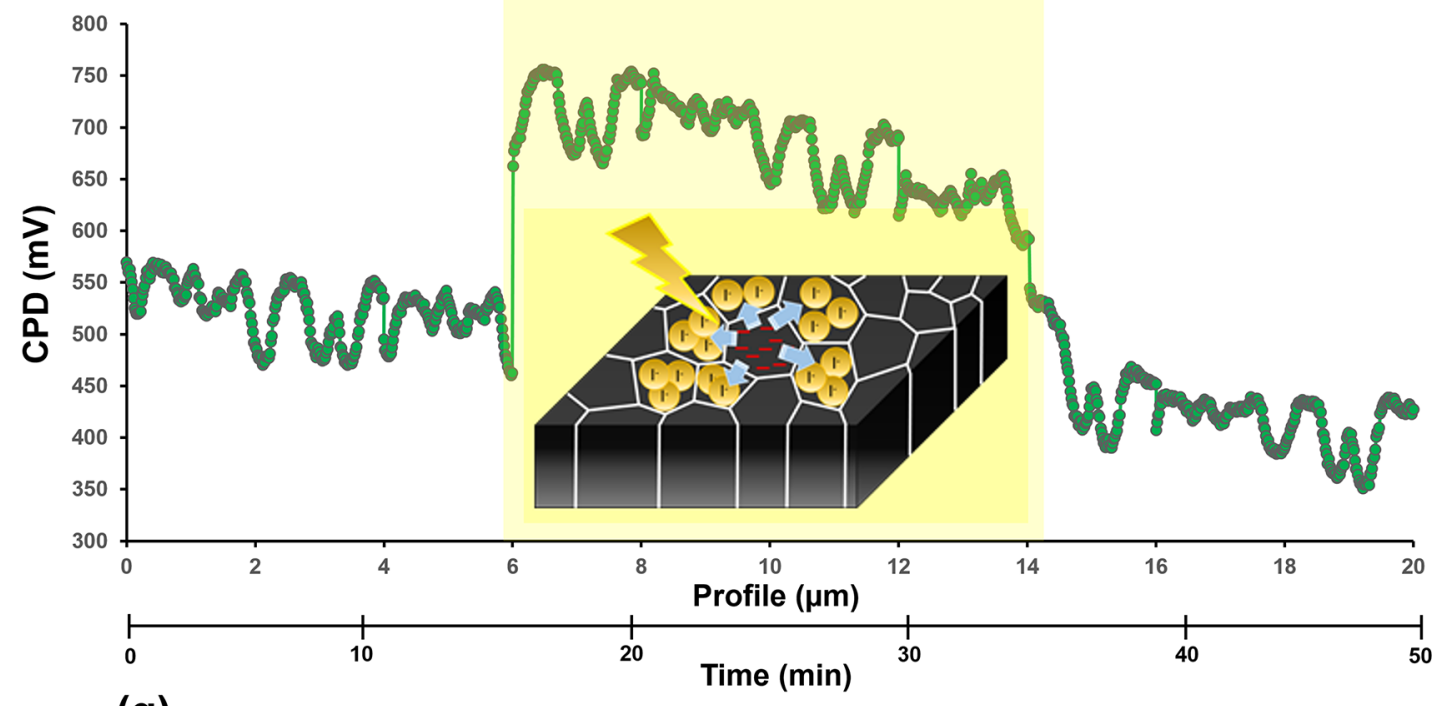

(g)

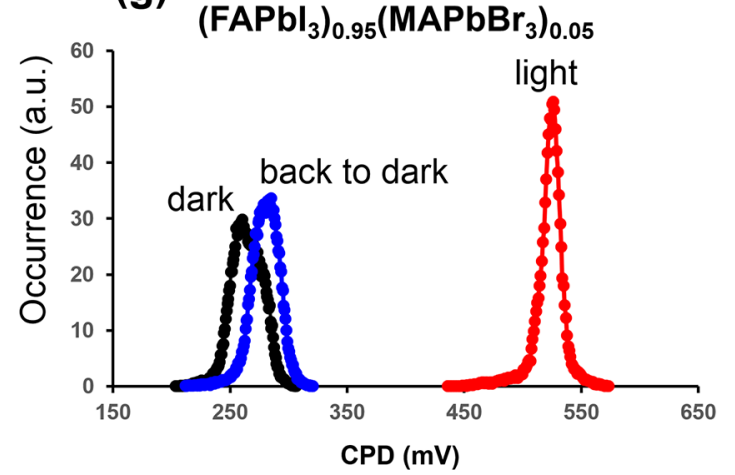

(h)

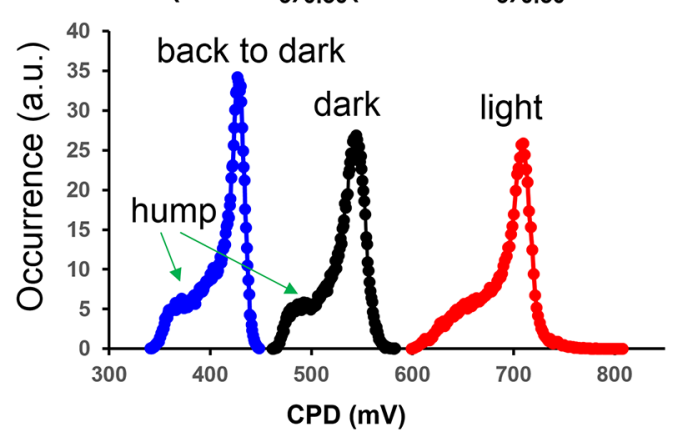

Figure 5. CPD mapping under illumination. Panels (a)-(e) are a series of CPD spatial maps with a sequence of LED light on and off for the $\left(\mathrm{FAPbI}_{3}\right)_{0.50}\left(\mathrm{MAPbBr}_{3}\right)_{0.50}$ composition. (f) CPD line profile of the white line in panels (a)-(e). Inset shows the spread of iodides from the flat grain with trap states under the illumination. Histograms of CPD distribution obtained from the CPD maps given in images (a)-(e) for the $(\mathrm{g})\left(\mathrm{FAPbI}_{3}\right)_{0.95}\left(\mathrm{MAPbBr}_{3}\right)_{0.05}$ and $(\mathrm{h})\left(\mathrm{FAPbI}_{3}\right)_{0.50}\left(\mathrm{MAPbBr}_{3}\right)_{0.50}$ composition.

ferroelectric polarization has been reported in $\mathrm{MAPbI}_{3}^{52,53}$ and as shown above, the flat grains are rich in $\mathrm{MA}, \mathrm{Pb}$, and $\mathrm{I}$. Generally, the dipole moment associated with MA cation in $\mathrm{MAPbI}_{3}$ perovskites leads to polarization due to large freedom of this organic cation motion, whereas FA-based perovskites have a more rigid structure with strong bonding between FA cations and inorganic cages. ${ }^{63}$ Regardless of whether the switching behavior of the flat grains originates from the ferroelectricity, ion trapping, or charge accumulation, these hysteretic P-E loop results suggest that a number of flat grains can contribute to hysteretic behaviors observed in the light $J-V$ curves of the $\left(\mathrm{FAPbI}_{3}\right)_{0.70}\left(\mathrm{MAPbBr}_{3}\right)_{0.30}$ and (FAP-
$\left.\mathrm{bI}_{3}\right)_{0.50}\left(\mathrm{MAPbBr}_{3}\right)_{0.50}$ that contain a number of flat grains based-devices in Figure S4.

Further insight into the light-induced effects on individual grains was gained through assessing the time-dependent CPD variations in dark and under illumination, alternately. Figure $5 a-$ e show spatial CPD maps in dark and under $5 \mathrm{~mW} / \mathrm{cm}^{2}$ white LED illumination for $\left(\mathrm{FAPbI}_{3}\right)_{0.50}\left(\mathrm{MAPbBr}_{3}\right)_{0.50}$ composition, in which halide segregation occurs rapidly upon illumination (see SI Figure S3). The line profile associated with the white line across the images of Figure $5 \mathrm{a}-\mathrm{e}$ is shown in Figure 5f. After the light is turned on, the grains with lower $\mathrm{CPD}$, corresponding to the flat grains, expand toward the 
edges of the grain and further grow as time evolves, gradually approaching the GBs; see the left half of Figure 5d. Despite turning off the light (right half of Figure $5 \mathrm{~d}$ ), the already expanded dark regions seem not to return immediately to their initial state. Interestingly, rather than returning to their original state, the dark regions keep spreading outward and the grain boundaries are no more distinguishable. SI Figure S10 shows line profiles of a particular grain (Figure 5a, marked as black line) in dark, light (Figure 5c, red line), and after the light is turned off (Figure 5e, blue line). It can be seen that the lower CPD core spreads after the light turned on and further permeates over the grain boundaries. This strongly suggests that the flat grains are activate channels for ion migration under illumination, potentially involving I and MA that were confirmed to be present in the flat grains at greater portion than other chemical components which is illustrated in inset of Figure 5f. Note that activation energy for $\mathrm{Pb}$ migration is relatively higher than that of organic cations and halides. ${ }^{64}$ This phenomenon can be correlated with the $J-V$ hysteresis as the pristine elemental distribution is completely changed after the illumination. To compare this phenomenon with a stable composition, the same measurement procedure was conducted for $\left(\mathrm{FAPbI}_{3}\right)_{0.95}\left(\mathrm{MAPbBr}_{3}\right)_{0.05}$, which is shown in SI Figure S11. The average CPD with homogeneous distribution increases under illumination and the increased CPD almost promptly returns to the dark condition average value (see Figure $5 \mathrm{~g}$ ). In contrast, CPD distribution in (FAP$\left.\mathrm{bI}_{3}\right)_{0.50}\left(\mathrm{MAPbBr}_{3}\right)_{0.50}$ film does not relax immediately to the pristine state after exposure to illumination (see Figure 5h). The dark CPD distribution curve shows a hump (lower CPD) due to existence of the flat grains and another peak at $\sim 550$ $\mathrm{mV}$ represents CPDs of the regular grains. During the illumination, the hump is slightly flattened but stretches further to the lower CPD which is responsible for the spread of the halides (lower CPD). After the light is turned off, the hump reappears, and the occurrence of the regular grains that has a peak around $\sim 420 \mathrm{mV}$ increases compared to the initial dark condition. This implies that a CPD difference between flat and regular grains became larger after illumination due to the spread of halides from the center of the flat grains. Unlike Hoke et al. ${ }^{18}$ observed the reversible phase segregation within a few minutes, our nanoscale study on (FAP$\left.\mathrm{bI}_{3}\right)_{0.50}\left(\mathrm{MAPbBr}_{3}\right)_{0.50}$ reveals that the halides do not immediately returns to the original states in the flat grains.

\section{CONCLUSIONS}

In summary, we investigated microstructural heterogeneity in $\left(\mathrm{FAPbI}_{3}\right)_{x}\left(\mathrm{MAPbBr}_{3}\right)_{1-x}$ using KPFM measurements. Increased distribution of dark grains in CPD maps, corresponding to the flat grains in topographic images, was observed as the concentration of $\mathrm{MAPbBr}_{3}$ increases. Halide segregation under illumination occurs in both $\left(\mathrm{FAPbI}_{3}\right)_{0.70}\left(\mathrm{MAPbBr}_{3}\right)_{0.30}$ and $\left(\mathrm{FAPbI}_{3}\right)_{0.50}\left(\mathrm{MAPbBr}_{3}\right)_{0.50}$ compositions confirmed by PL measurements. Particularly, severe phase segregation appears in $\left(\mathrm{FAPbI}_{3}\right)_{0.50}\left(\mathrm{MAPbBr}_{3}\right)_{0.50}$. The measured solar cell device performances via $J-V$ measurements were superior in $\left(\mathrm{FAPbI}_{3}\right)_{0.95}\left(\mathrm{MAPbBr}_{3}\right)_{0.05}$, but the efficiency is gradually decreased with $\mathrm{MAPbBr}_{3}$ increase including the worst performance in $\left(\mathrm{FAPbI}_{3}\right)_{0.50}\left(\mathrm{MAPbBr}_{3}\right)_{0.50}$. The chemical imaging analysis reveals that the flat grains comprise of higher I component. This is in good agreement with the laserwavelength dependent KPFM results that showed the flat grains have a higher SPV under $720 \mathrm{~nm}$. Despite the ferroelectric-like behavior of the flat grains in PFM imaging, there was no ferroelectricity in the high-speed induced PFM loop. Such dynamics are strongly associated with ion migration or charge carrier trapping. We found that under white LED illumination, dark regions in the flat grains provide a source of ion migration, revealing irreversible CPD distribution between dark and illumination. These results clearly show the significance of compositional engineering and highlight that appropriate grain engineering via nanoscale composition tuning is critically important for highly efficient and stable OIHPs. Further understanding of the flat grain formation mechanisms is necessary to improve the performance of largebandgap mixed-halide perovskite devices.

\section{EXPERIMENTAL SECTION}

Perovskite Synthesis and Device Fabrication. Laser-etched FTO glass substrates were precleaned with DI water, acetone, and IPA in an ultrasonic bath for 15 min, respectively. $\mathrm{A} \mathrm{SnO}_{2}$ layer was deposited on the precleaned substrate by chemical bath deposition in accordance with a previous report. ${ }^{65}$ Then, the substrate was annealed at $150{ }^{\circ} \mathrm{C}$ for $1 \mathrm{~h}$. The desired $\left(\mathrm{FAPbI}_{3}\right)_{x}\left(\mathrm{MAPbBr}_{3}\right)_{1-x}$ precursor solution with $1.44 \mathrm{M}$ were prepared by dissolving $\mathrm{FAI}, \mathrm{PbI}_{2}$, and

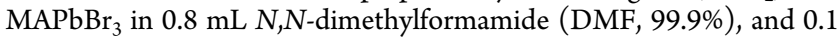
$\mathrm{mL}$ dimethyl sulfoxide (DMSO, 99.7\%). MACl (35 mol \%) was added in all the precursor solutions. The prepared precursor solutions were spin-coated at $1000 \mathrm{rpm}$ for $5 \mathrm{~s}$ following by $5000 \mathrm{rpm}$ for $30 \mathrm{~s}$ where $1 \mathrm{~mL}$ of diethyl ether was dropped during this stage. Finally, the samples were annealed at $150{ }^{\circ} \mathrm{C}$ for $10 \mathrm{~min}$. For hole transporting layer, the precursor solution containing $100 \mathrm{mg}$ SprioOMeTAD in $1.1 \mathrm{~mL}$ chlorobenzene with $23 \mu \mathrm{L} \mathrm{Li}$-TFSI $(540 \mathrm{mg} / \mathrm{mL}$ in acetonitrile) and $10 \mu \mathrm{L}$ cobalt-TFSI $(735 \mathrm{mg} / \mathrm{mL}$ in acetonitrile) and $39 \mu \mathrm{L}$ of 4-tert-butylpyridine was spin-coated on the perovskite films coated substrate at $2000 \mathrm{rpm}$ for $30 \mathrm{~s}$. A $130 \mathrm{~nm}$ gold electrode was deposited by thermal evaporation.

\section{CHARACTERIZATIONS}

$J-V, \mathrm{PL}$, and EQE Measurements. Current DensityVoltage $(J-V)$ Measurements. The $J-V$ measurements were performed using a solar cell $I-V$ testing system that includes a class AAA solar simulator and Keithley 2400 source meter under an illumination power of $100 \mathrm{~mW} \mathrm{~cm} \mathrm{~cm}^{-2}$ with a 0.094 $\mathrm{cm}^{2}$ aperture and a scan rate of $0.1 \mathrm{~V} / \mathrm{s}$. All $J-V$ measurements were undertaken at room temperature in ambient conditions.

Photoluminescence (PL) Measurements. The time-resolved PL measurements upon one-photo excitation were conducted using an Andor iVac CCD detector whose temperature was $30{ }^{\circ} \mathrm{C}$. Each luminescence was excited with a $409 \mathrm{~nm}$ wavelength light, and exposure time was set to $2 \mathrm{~s}$ for $\left(\mathrm{FAPbI}_{3}\right)_{x}\left(\mathrm{MAPbBr}_{3}\right)_{1-x}$ Perovskite films using a PerkinElmer LAMBDA $1050 \mathrm{UV} /$ vis/NIR spectrophotometer. Timeresolved PL measurements were carried out under 1 sun illumination $\left(100 \mathrm{~mW} / \mathrm{cm}^{2}\right)$ by a solar simulator.

External Quantum Efficiency (EQE) Measurements. The EQE spectra were obtained from 310 to $900 \mathrm{~nm}$ using QuantX-300, Newport.

Chemical Analysis: ToF-SIMS, TEM, and AFM-IR Measurements. Time-of-Flight-Secondary lon Mass Spectrometry (ToF-SIMS) Measurements. ToF-SIMS measurements were performed using ToF.SIMS5NCS instrument (IONTOF GmbH, Germany). Experiments were carried out in both negative and positive ion modes with spectra calibrated using the $\mathrm{I}^{-}, \mathrm{Br}^{-}, \mathrm{MA}^{+}, \mathrm{FA}^{+}$, and $\mathrm{Pb}^{+}$peaks.

Transmission Electron Microscopy (TEM)-Energy Dispersive X-ray Spectroscopy (EDS) Measurements. The cross- 
sectional lamella of the sample was milled using a dual-beam Focus ion beam (FIB) FEI Nova NanoLab 200. The lamella was placed on a carbon-coated copper grid via an out-situ liftout method (Kleindiek micromanipulator). The HR-TEM images and EDS analyses of the lamella were obtained using a Philips CM200 field emission transmission electron microscope (Eindhoven, The Netherlands) with an attached Bruker QUANTAX energy dispersive X-ray spectroscopy system (EDX).

Atomic Force Microscopy Infrared Spectroscopy (AFM-IR) Measurements. All experimental AFM-IR were performed using Anasys NanoIR2-s instrument with spectral ranges 916$1864 \mathrm{~cm}^{-1}$. Commercially available NanoIR probes for contact mode with force constants $0.07 \mathrm{~N} / \mathrm{m}$ were used.

SPM: KPFM and PFM Measurements. Kelvin Probe Force Microscopy (KPFM) and Piezoresponse Force Microscopy (PFM) Measurements. KPFM and PFM measurements were carried out using a commercial AFM (AIST-NT SmartSPM 1000) in KPFM and PFM modes under ambient condition. The samples were measured immediately after they were transferred out of the $\mathrm{N}_{2}$-filled glovebox. Consistent results have been achieved from repetitive measurements. KPFM and PFM measurements were performed using a diamond-like carbon (DLC) coated conductive probe (DCP20, NT-MDTForce constant, $k=48 \mathrm{~N} / \mathrm{m}$ ) Si cantilevers and Pt-coated Si cantilever (HQ:CSC 37/PT, $\mu$ masch, Force constant, $k=0.8 \mathrm{~N} / \mathrm{m}$ ), respectively. A built-in white LED light source was used to illuminate the sample with maximum intensity $\left(5 \mathrm{~mW} / \mathrm{cm}^{2}\right)$. The intensity of the light was measured with an S120C silicon photodiode detector integrated with a PM100D optical power and energy meter (Thorlabs, Germany).

\section{ASSOCIATED CONTENT}

\section{St Supporting Information}

The Supporting Information is available free of charge at https://pubs.acs.org/doi/10.1021/acsnano.1c08726.

Additional Figures $\mathrm{S} 1-\mathrm{S} 13$ include topography images of $\left(\mathrm{FAPbI}_{3}\right)_{x}\left(\mathrm{MAPbBr}_{3}\right)_{1-x}$ perovskite films, height line profiles of regular and flat grain, $\mathrm{PL}$ spectra for four different composition of $\left(\mathrm{FAPbI}_{3}\right)_{x}\left(\mathrm{MAPbBr}_{3}\right)_{1-x}$ perovskite films, CPD spatial maps and AFM topography of $\left(\mathrm{FAPbI}_{3}\right)_{0.85}\left(\mathrm{MAPbBr}_{3}\right)_{0.15}$ perovskite films as a function of annealing time, $\mathrm{J}-\mathrm{V}$ characteristics and EQE spectra in $\left(\mathrm{FAPbI}_{3}\right)_{x}\left(\mathrm{MAPbBr}_{3}\right)_{1-x}$ devices, chemical maps obtained from ToF-SIMS, NMF analysis of Nano-IR data, amplitude distribution curves in Nano-IR data, AFM topography, CPD line profiles, CPD spatial maps, and line profile in $\left(\mathrm{FAPbI}_{3}\right)_{0.95}\left(\mathrm{MAPbBr}_{3}\right)_{0.05}$ perovskite films (PDF)

\section{AUTHOR INFORMATION}

\section{Corresponding Authors}

Arman Mahboubi Soufiani - Australian Centre for Advanced Photovoltaics (ACAP), School of Photovoltaic and Renewable and Engineering, University of New South Wales, Sydney, New South Wales 2052, Australia;

Email: a.mahboubisoufiani@unsw.edu.au

Jun Hong Noh - School of Civil, Environmental and Architectural Engineering, Korea University, Seoul 02841, Republic of Korea; (ㅇ) orcid.org/0000-0002-1143-5822; Email: junhnoh@korea.ac.kr
Jae Sung Yun - Australian Centre for Advanced Photovoltaics (ACAP), School of Photovoltaic and Renewable and Engineering, University of New South Wales, Sydney, New South Wales 2052, Australia; Department of Electrical and Electronic Engineering, Advanced Technology Institute (ATI), University of Surrey, Guildford GU2 7XH, U.K.; Email: j.yun@unsw.edu.au

\section{Authors}

Dohyung Kim - School of Materials Science and Engineering, University of New South Wales, Sydney, New South Wales 2052, Australia; Joint Institute for Advanced Materials, Department of Materials Science and Engineering, University of Tennessee, Knoxville, Tennessee 37996, United States; (1) orcid.org/0000-0002-1586-1466

Jihoo Lim - Australian Centre for Advanced Photovoltaics (ACAP), School of Photovoltaic and Renewable and Engineering, University of New South Wales, Sydney, New South Wales 2052, Australia

Seungmin Lee - School of Civil, Environmental and Architectural Engineering, Korea University, Seoul 02841, Republic of Korea

Eunyoung Choi - Australian Centre for Advanced Photovoltaics (ACAP), School of Photovoltaic and Renewable and Engineering, University of New South Wales, Sydney, New South Wales 2052, Australia; (1) orcid.org/0000-00016923-8015

Anton V. Ievlev - The Center for Nanophase Materials Sciences, Oak Ridge National Laboratory, Oak Ridge, Tennessee 37831, United States; 다이.org/0000-00033645-0508

Nikolay Borodinov - The Center for Nanophase Materials Sciences, Oak Ridge National Laboratory, Oak Ridge, Tennessee 37831, United States; 다이.org/0000-00028562-5629

Yongtao Liu - The Center for Nanophase Materials Sciences, Oak Ridge National Laboratory, Oak Ridge, Tennessee 37831, United States; (1) orcid.org/0000-0003-0152-1783

Olga S. Ovchinnikova - Computational Sciences and Engineering Division, Oak Ridge National Laboratory, Oak Ridge, Tennessee 37830, United States; 이 orcid.org/00000001-8935-2309

Mahshid Ahmadi - Joint Institute for Advanced Materials, Department of Materials Science and Engineering, University of Tennessee, Knoxville, Tennessee 37996, United States; (1) orcid.org/0000-0002-3268-7957

Sean Lim - Electron Microscope Unit, University of New South Wales, Sydney, New South Wales 2052, Australia

Pankaj Sharma - School of Materials Science and Engineering, University of New South Wales, Sydney, New South Wales 2052, Australia; orcid.org/0000-0002-8108-9339

Jan Seidel - School of Materials Science and Engineering, University of New South Wales, Sydney, New South Wales 2052, Australia; (1) orcid.org/0000-0003-2814-3241

Complete contact information is available at:

https://pubs.acs.org/10.1021/acsnano.1c08726

\section{Author Contributions}

${ }^{\mathrm{I}}$ D.K., J.L., and S. L. contributed equally to this work.

\section{Author Contributions}

D.K., J.L., and S.L. contributed equally to this work. J.S.Y., P.S., J.S., and D.K. conceived the project and J.S.Y. designed the experiments. J.H.N. and S.L. fabricated the compositional- 
dependent perovskite films, and solar cell devices and tested JV curves. D.K. and J.S.Y. performed the KPFM, AFM, and PFM measurements supported by J.S. The chemical imaging measurements were supported from O.S.O., N.B., and A.I.V., Y.L., and D.K. performed the AFM-IR measurements with help from N.B. and Y.L., and support from M.A. The AFM-IR data was analyzed by N.B. and A.I.V. performed the ToF-SIMS measurements and analyzed the data. S.L. performed the TEM-EDS measurements and analyzed data. A.M.S., E.C., J.L., and J.S.Y. performed additional KPFM and PL measurements. D.K., J.L., A.M.S., and J.S.Y. wrote the manuscript. All the authors contributed to the revision of manuscript and discussions.

\section{Notes}

The authors declare no competing financial interest.

\section{ACKNOWLEDGMENTS}

D.K., J.S., and J.S.Y. acknowledge support from CNMS user facility. The ToF-SIMS and Nano-IR measurements were conducted and supported by A.V.I., N.B., Y.L., and O.S.O. at the Center for Nanophase Materials Sciences (CNMS), which is DOE Office of Science User Facility in the United States. A.M.S. acknowledges the funding support from the Australian Centre for Advanced Photovoltaics (RG193402-I). D.K. thanks Dr. Sergei V. Kalinin for useful discussion. This study was supported by the National Research Foundation of Korea (NRF) grant funded by the Korea Government (MSIP) (Grant Nos. NRF-2020R1A2C3009115)

\section{REFERENCES}

(1) Kojima, A.; Teshima, K.; Shirai, Y.; Miyasaka, T. Organometal Halide Perovskites as Visible-Light Sensitizers for Photovoltaic Cells. J. Am. Chem. Soc. 2009, 131, 6050-6051.

(2) Saidaminov, M. I.; Adinolfi, V.; Comin, R.; Abdelhady, A. L.; Peng, W.; Dursun, I.; Yuan, M.; Hoogland, S.; Sargent, E. H.; Bakr, O. M. Planar-Integrated Single-Crystalline Perovskite Photodetectors. Nat. Commun. 2015, 6, 8724.

(3) Kovalenko, M. V.; Protesescu, L.; Bodnarchuk, M. I. Properties and Potential Optoelectronic Applications of Lead Halide Perovskite Nanocrystals. Science 2017, 358, 745.

(4) Ball, J. M.; Lee, M. M.; Hey, A.; Snaith, H. J. Low-Temperature Processed Meso-Superstructured to Thin-Film Perovskite Solar Cells. Energy Environ. Sci. 2013, 6, 1739-1743.

(5) Green, M. A.; Ho-Baillie, A.; Snaith, H. J. The Emergence of Perovskite Solar Cells. Nat. Photonics 2014, 8, 506-514.

(6) Jeon, N. J.; Noh, J. H.; Kim, Y. C.; Yang, W. S.; Ryu, S.; Seok, S. I. Solvent Engineering for High-Performance Inorganic-Organic Hybrid Perovskite Solar Cells. Nat. Mater. 2014, 13, 897-903.

(7) NREL: Best Research-Cell Efficiency Chart. 2021, https://www. nrel.gov/pv/cell-efficiency.html (accessed 2021/10/11).

(8) Jacobs, D. A.; Langenhorst, M.; Sahli, F.; Richards, B. S.; White, T. P.; Ballif, C.; Catchpole, K. R.; Paetzold, U. W. Light Management: A Key Concept in High-Efficiency Perovskite/Silicon Tandem Photovoltaics. J. Phys. Chem. Lett. 2019, 10, 3159-3170.

(9) Kim, D.; Jung, H. J.; Park, I. J.; Larson, B. W.; Dunfield, S. P.; Xiao, C.; Kim, J.; Tong, J.; Boonmongkolras, P.; Ji, S. G.; Zhang, F.; Pae, S. R.; Kim, M.; Kang, S. B.; Dravid, V.; Berry, J. J.; Kim, J. Y.; Zhu, K.; Kim, D. H.; Shin, B. Efficient, Stable Silicon Tandem Cells Enabled by Anion-Engineered Wide-Bandgap Perovskites. Science 2020, 368, 155 .

(10) Gharibzadeh, S.; Hossain, I. M.; Fassl, P.; Nejand, B. A.; Abzieher, T.; Schultes, M.; Ahlswede, E.; Jackson, P.; Powalla, M.; Schäfer, S.; Rienäcker, M.; Wietler, T.; Peibst, R.; Lemmer, U.; Richards, B. S.; Paetzold, U. W. 2D/3D Heterostructure for Semitransparent Perovskite Solar Cells with Engineered Bandgap
Enables Efficiencies Exceeding 25\% in Four-Terminal Tandems with Silicon and CIGS. Adv. Funct. Mater. 2020, 30, 1909919.

(11) Al-Ashouri, A.; Köhnen, E.; Li, B.; Magomedov, A.; Hempel, H.; Caprioglio, P.; Márquez José, A.; Vilches, A. B. M.; Kasparavicius, E.; Smith, J. A.; Phung, N.; Menzel, D.; Crischek, M.; Kegelmann, L.; Skroblin, D.; Gollwitzer, C.; Malinauskas, T.; Jost, M.; Matic, G.; Rech, B.; Schlatmann, R.; Topic, M.; Korte, L.; Abate, A.; Stannowski, B.; Neher, D.; Stolterfoht, M.; Unold, T.; Getautis, V.; et al. Monolithic Perovskite/Silicon Tandem Solar Cell with > 29\% Efficiency by Enhanced Hole Extraction. Science 2020, 370, 13001309.

(12) Bush, K. A.; Frohna, K.; Prasanna, R.; Beal, R. E.; Leijtens, T.; Swifter, S. A.; McGehee, M. D. Compositional Engineering for Efficient Wide Band Gap Perovskites with Improved Stability to Photoinduced Phase Segregation. ACS Energy Lett. 2018, 3, 428-435.

(13) Wu, M.-J.; Kuo, C.-C.; Jhuang, L.-S.; Chen, P.-H.; Lai, Y.-F.; Chen, F.-C. Bandgap Engineering Enhances the Performance of Mixed-Cation Perovskite Materials for Indoor Photovoltaic Applications. Adv. Energy Mater. 2019, 9, 1901863.

(14) Jeon, N. J.; Noh, J. H.; Yang, W. S.; Kim, Y. C.; Ryu, S.; Seo, J.; Seok, S. I. Compositional Engineering of Perovskite Materials for High-Performance Solar Cells. Nature 2015, 517, 476-480.

(15) Correa-Baena, J.-P.; Saliba, M.; Buonassisi, T.; Grätzel, M.; Abate, A.; Tress, W.; Hagfeldt, A. Promises and Challenges of Perovskite Solar Cells. Science 2017, 358, 739.

(16) Wang, L.; Wang, G.; Yan, Z.; Qiu, J.; Jia, C.; Zhang, W.; Zhen, C.; Xu, C.; Tai, K.; Jiang, X.; Yang, S. Potassium-Induced Phase Stability Enables Stable and Efficient Wide-Bandgap Perovskite Solar Cells. Solar RRL 2020, 4, 2000098.

(17) Knight, A. J.; Wright, A. D.; Patel, J. B.; McMeekin, D. P.; Snaith, H. J.; Johnston, M. B.; Herz, L. M. Electronic Traps and Phase Segregation in Lead Mixed-Halide Perovskite. ACS Energy Lett. 2019, $4,75-84$.

(18) Hoke, E. T.; Slotcavage, D. J.; Dohner, E. R.; Bowring, A. R.; Karunadasa, H. I.; McGehee, M. D. Reversible Photo-Induced Trap Formation in Mixed-Halide Hybrid Perovskites for Photovoltaics. Chem. Sci. 2015, 6, 613-617.

(19) McMeekin, D. P.; Sadoughi, G.; Rehman, W.; Eperon, G. E.; Saliba, M.; Hörantner, M. T.; Haghighirad, A.; Sakai, N.; Korte, L.; Rech, B.; Johnston, M. B.; Herz, L. M.; Snaith, H. J. A Mixed-Cation Lead Mixed-Halide Perovskite Absorber for Tandem Solar Cells. Science 2016, 351, 151.

(20) Syzgantseva, O. A.; Saliba, M.; Grätzel, M.; Rothlisberger, U. Stabilization of the Perovskite Phase of Formamidinium Lead Triiodide by Methylammonium, Cs, and/or Rb Doping. J. Phys. Chem. Lett. 2017, 8, 1191-1196.

(21) Saliba, M.; Matsui, T.; Seo, J.-Y.; Domanski, K.; Correa-Baena, J.-P.; Nazeeruddin, M. K.; Zakeeruddin, S. M.; Tress, W.; Abate, A.; Hagfeldt, A.; Grätzel, M. Cesium-Containing Triple Cation Perovskite Solar Cells: Improved Stability, Reproducibility and High Efficiency. Energy Environ. Sci. 2016, 9, 1989-1997.

(22) Yang, J.; Hong, Q.; Yuan, Z.; Xu, R.; Guo, X.; Xiong, S.; Liu, X.; Braun, S.; Li, Y.; Tang, J.; Duan, C.; Fahlman, M.; Bao, Q. Unraveling Photostability of Mixed Cation Perovskite Films in Extreme Environment. Adv. Opt. Mater. 2018, 6, 1800262.

(23) Zheng, X.; Hou, Y.; Bao, C.; Yin, J.; Yuan, F.; Huang, Z.; Song, K.; Liu, J.; Troughton, J.; Gasparini, N.; Zhou, C.; Lin, Y.; Xue, D.-J.; Chen, B.; Johnston, A. K.; Wei, N.; Hedhili, M. N.; Wei, M.; Alsalloum, A. Y.; Maity, P.; et al. Managing Grains and Interfaces via Ligand Anchoring Enables 22.3\%-Efficiency Inverted Perovskite Solar Cells. Nat. Energy 2020, 5, 131-140.

(24) Tennyson, E. M.; Doherty, T. A. S.; Stranks, S. D. Heterogeneity at Multiple Length Scales in Halide Perovskite Semiconductors. Nat. Rev. Mater. 2019, 4, 573-587.

(25) Correa-Baena, J.-P.; Luo, Y.; Brenner, T. M.; Snaider, J.; Sun, S.; Li, X.; Jensen, M. A.; Hartono, N. T. P.; Nienhaus, L.; Wieghold, S.; Pindexter, J. R.; Wang, S.; Meng, Y. S.; Wang, T.; Lai, B.; Holt, M. V.; Cai, Z.; Bawendi, M. G.; Huang, L.; Buonassisi, T.; et al. 
Homogenized Halides and Alkali Cation Segregation in Alloyed Organic-Inorganic Perovskites. Science 2019, 363, 627.

(26) Doherty, T. A. S.; Winchester, A. J.; Macpherson, S.; Johnstone, D. N.; Pareek, V.; Tennyson, E. M.; Kosar, S.; Kosasih, F. U.; Anaya, M.; Abdi-Jalebi, M.; Andaji-Garmaroudi, Zahra; Wong, E. L.; Madéo, J.; Chiang, Y.-H.; Park, J.-S.; Jung, Y.-K.; Petoukhoff, C. E.; Divitini, G.; Man, M. K. L.; Ducati, C.; et al. Performance-Limiting Nanoscale Trap Clusters at Grain Junctions in Halide Perovskites. Nature 2020, 580, 360-366.

(27) Wieghold, S.; Tresback, J.; Correa-Baena, J.-P.; Hartono, N. T. P.; Sun, S.; Liu, Z.; Layurova, M.; VanOrman, Z. A.; Bieber, A. S.; Thapa, J.; Lai, B.; Cai, Z.; Nienhaus, L.; Buonassisi, T. Halide Heterogeneity Affects Local Charge Carrier Dynamics in Mixed-Ion Lead Perovskite Thin Films. Chem. Mater. 2019, 31, 3712-3721.

(28) deQuilettes, D. W.; Jariwala, S.; Burke, S.; Ziffer, M. E.; Wang, J. T. W.; Snaith, H. J.; Ginger, D. S. Tracking Photoexcited Carriers in Hybrid Perovskite Semiconductors: Trap-Dominated Spatial Heterogeneity and Diffusion. ACS Nano 2017, 11, 11488-11496.

(29) de Quilettes, D. W.; Vorpahl, S. M.; Stranks, S. D.; Nagaoka, H.; Eperon, G. E.; Ziffer, M. E.; Snaith, H. J.; Ginger, D. S. Impact of Microstructure on Local Carrier Lifetime in Perovskite Solar Cells. Science 2015, 348, 683.

(30) Jones, T. W.; Osherov, A.; Alsari, M.; Sponseller, M.; Duck, B. C.; Jung, Y.-K.; Settens, C.; Niroui, F.; Brenes, R.; Stan, C. V.; Li, Y.; Abdi-Jalebi, M.; Tamura, N.; Macdonald, J. E.; Burghammer, M.; Friend, R. H.; Bulović, V.; Walsh, A.; Wilson, G. J.; Lilliu, S.; et al. Lattice Strain Causes Non-Radiative Losses in Halide Perovskites. Energy Environ. Sci. 2019, 12, 596-606.

(31) Draguta, S.; Thakur, S.; Morozov, Y. V.; Wang, Y.; Manser, J. S.; Kamat, P. V.; Kuno, M. Spatially Non-uniform Trap State Densities in Solution-Processed Hybrid Perovskite Thin Films. J. Phys. Chem. Lett. 2016, 7, 715-721.

(32) Bischak, C. G.; Hetherington, C. L.; Wu, H.; Aloni, S.; Ogletree, D. F.; Limmer, D. T.; Ginsberg, N. S. Origin of Reversible Photoinduced Phase Separation in Hybrid Perovskites. Nano Lett. 2017, 17, 1028-1033.

(33) Rehman, W.; McMeekin, D. P.; Patel, J. B.; Milot, R. L.; Johnston, M. B.; Snaith, H. J.; Herz, L. M. Photovoltaic Mixed-Cation Lead Mixed-Halide Perovskites: Links between Crystallinity, Photostability and Electronic Properties. Energy Environ. Sci. 2017, 10, 361369.

(34) Zhang, H.; Fu, X.; Tang, Y.; Wang, H.; Zhang, C.; Yu, W. W.; Wang, X.; Zhang, Y.; Xiao, M. Phase Segregation due to Ion migration in All-Inorganic Mixed-Halide Perovskite Nanocrystals. Nat. Commun. 2019, 10, 1088.

(35) Gratia, P.; Grancini, G.; Audinot, J.-N.; Jeanbourquin, X.; Mosconi, E.; Zimmermann, I.; Dowsett, D.; Lee, Y.; Grätzel, M.; Angelis, F. D.; Sivula, K.; Wirtz, T.; Nazeeruddin, M. K. Intrinsic Halide Segregation at Nanometer Scale Determines the High Efficiency of Mixed Cation/Mixed Halide Perovskite Solar Cells. J. Am. Chem. Soc. 2016, 138, 15821-15824.

(36) Xu, Z.; Liu, Z.; Li, N.; Tang, G.; Zheng, G.; Zhu, C.; Chen, Y.; Wang, L.; Huang, Y.; Li, L.; Zhou, N.; Hong, J.; Chen, Q.; Zhou, H. A Thermodynamically Favored Crystal Orientation in Mixed Formamidinium/Methylammonium Perovskite for Efficient Solar Cells. Adv. Mater. 2019, 31, 1900390.

(37) Noh, J. H.; Im, S. H.; Heo, J. H.; Mandal, T. N.; Seok, S. I. Chemical Management for Colorful, Efficient, and Stable InorganicOrganic Hybrid Nanostructured Solar Cells. Nano Lett. 2013, 13, 1764-1769.

(38) Jesper Jacobsson, T.; Correa-Baena, J.-P.; Pazoki, M.; Saliba, M.; Schenk, K.; Grätzel, M.; Hagfeldt, A. Exploration of the Compositional Space for Mixed Lead Halogen Perovskites for High Efficiency Solar Cells. Energy Environ. Sci. 2016, 9, 1706-1724.

(39) Deretzis, I.; Alberti, A.; Pellegrino, G.; Smecca, E.; Giannazzo, F.; Sakai, N.; Miyasaka, T.; La Magna, A. Atomistic Origins of $\mathrm{CH}_{3} \mathrm{NH}_{3} \mathrm{PbI}_{3}$ Degradation to $\mathrm{PbI}_{2}$ in Vacuum. Appl. Phys. Lett. 2015, 106, 131904.
(40) Jiang, Y.; Yang, S.-C.; Jeangros, Q.; Pisoni, S.; Moser, T.; Buecheler, S.; Tiwari, A. N.; Fu, F. Mitigation of Vacuum and Illumination-Induced Degradation in Perovskite Solar Cells by Structure Engineering. Joule 2020, 4, 1087-1103.

(41) Zhou, Y.; Zhao, Y. Chemical Stability and Instability of Inorganic Halide Perovskites. Energy Environ. Sci. 2019, 12, 14951511.

(42) Szostak, R.; Silva, J. C.; Turren-Cruz, S. H.; Soares, M. M.; Freitas, R. O.; Hagfeldt, A.; Tolentino, H. C. N.; Nogueira, A. F. Nanoscale Mapping of Chemical Composition in Organic-Inorganic Hybrid Perovskite Films. Sci. Adv. 2019, 5, eaaw6619.

(43) Higgins, K.; Lorenz, M.; Ziatdinov, M.; Vasudevan, R. K.; Ievlev, A. V.; Lukosi, E. D.; Ovchinnikova, O. S.; Kalinin, S. V.; Ahmadi, M. Exploration of Electrochemical Reactions at OrganicInorganic Halide Perovskite Interfaces via Machine Learning in in Situ Time-of-Flight Secondary Ion Mass Spectrometry. Adv. Funct. Mater. 2020, 30, 2001995.

(44) Liu, Y.; Ievlev, A. V.; Borodinov, N.; Lorenz, M.; Xiao, K.; Ahmadi, M.; Hu, B.; Kalinin, S. V.; Ovchinnikova, O. S. Direct Observation of Photoinduced Ion Migration in Lead Halide Perovskites. Adv. Funct. Mater. 2021, 31, 2008777.

(45) Brenner, T. M.; Rakita, Y.; Orr, Y.; Klein, E.; Feldman, I.; Elbaum, M.; Cahen, D.; Hodes, G. Conversion of Single Crystalline $\mathrm{PbI}_{2}$ to $\mathrm{CH}_{3} \mathrm{NH}_{3} \mathrm{PbI}_{3}$ : Structural Relations and Transformation Dynamics. Chem. Mater. 2016, 28, 6501-6510.

(46) Sinha, S.; Zhu, T.; France-Lanord, A.; Sheng, Y.; Grossman, J. C.; Porfyrakis, K.; Warner, J. H. Atomic Structure and Defect Dynamics of Monolayer Lead Iodide Nanodisks with Epitaxial Alignment on Graphene. Nat. Commun. 2020, 11, 823.

(47) Kim, J.; Park, B.; Baek, J.; Yun, J. S.; Kwon, H.-W.; Seidel, J.; Min, H.; Coelho, S.; Lim, S.; Huang, S.; Gaus, K.; Green, M. A.; Shin, T. J.; Ho-baillie, A. W. Y.; Kim, M. G.; Seok, S. I. Unveiling the Relationship between the Perovskite Precursor Solution and the Resulting Device Performance. J. Am. Chem. Soc. 2020, 142, 62516260.

(48) Park, J.-S.; Calbo, J.; Jung, Y.-K.; Whalley, L. D.; Walsh, A. Accumulation of Deep Traps at Grain Boundaries in Halide Perovskites. ACS Energy Lett. 2019, 4, 1321-1327.

(49) Yun, J. S.; Seidel, J.; Kim, J.; Soufiani, A. M.; Huang, S.; Lau, J.; Jeon, N. J.; Seok, S. I.; Green, M. A.; Ho-Baillie, A. Critical Role of Grain Boundaries for Ion Migration in Formamidinium and Methylammonium Lead Halide Perovskite Solar Cells. Adv. Energy Mater. 2016, 6, 1600330.

(50) Kim, D.; Yun, J. S.; Sharma, P.; Lee, D. S.; Kim, J.; Soufiani, A. M.; Huang, S.; Green, M. A.; Ho-Baillie, A. W. Y.; Seidel, J. Light- and Bias-Induced Structural Variations in Metal Halide Perovskites. Nat. Commun. 2019, 10, 444.

(51) Röhm, H.; Leonhard, T.; Hoffmann, M. J.; Colsmann, A. Ferroelectric Domains in Methylammonium Lead Iodide Perovskite Thin-Films. Energy Environ. Sci. 2017, 10, 950-955.

(52) Rakita, Y.; Bar-Elli, O.; Meirzadeh, E.; Kaslasi, H.; Peleg, Y.; Hodes, G.; Lubomirsky, I.; Oron, D.; Ehre, D.; Cahen, D. Tetragonal $\mathrm{CH}_{3} \mathrm{NH}_{3} \mathrm{PbI}_{3}$ is Ferroelectric. Proc. Natl. Acad. Sci. 2017, 114.

(53) Garten, L. M.; Moore, D. T.; Nanayakkara, S. U.; Dwaraknath, S.; Schulz, P.; Wands, J.; Rockett, A.; Newell, B.; Persson, K. A.; Trolier-McKinstry, S.; Ginley, D. S. The Existence and Impact of Persistent Ferroelectric Domains in $\mathrm{MAPbI}_{3}$. Sci. Adv. 2019, 5, eaas9311.

(54) Röhm, H.; Leonhard, T.; Hoffmann, M. J.; Colsmann, A. Ferroelectric Poling of Methylammonium Lead Iodide Thin Films. Adv. Funct. Mater. 2020, 30, 1908657.

(55) Hermes, I. M.; Bretschneider, S. A.; Bergmann, V. W.; Li, D.; Klasen, A.; Mars, J.; Tremel, W.; Laquai, F.; Butt, H.-J.; Mezger, M.; Berger, R.; Rodriguez, B. J.; Weber, S. A. L. Ferroelastic Fingerprints in Methylammonium Lead Iodide Perovskite. J. Phys. Chem. C 2016, 120, 5724-5731.

(56) Strelcov, E.; Dong, Q.; Li, T.; Chae, J.; Shao, Y.; Deng, Y.; Gruverman, A.; Huang, J.; Centrone, A. $\mathrm{CH}_{3} \mathrm{NH}_{3} \mathrm{PbI}_{3}$ Perovskites: Ferroelasticity Revealed. Sci. Adv. 2017, 3, e1602165. 
(57) Liu, Y.; Collins, L.; Proksch, R.; Kim, S.; Watson, B. R.; Doughty, B.; Calhoun, T. R.; Ahmadi, M.; Ievlev, A. V.; Jesse, S.; Retterer, S. T.; Belianinov, A.; Xiao, K.; Huang, J.; Sumpter, B. G.; Kalinin, S. V.; Hu, B.; Ovchinnikova, O. S. Chemical Nature of Ferroelastic Twin Domains in $\mathrm{CH}_{3} \mathrm{NH}_{3} \mathrm{PbI}_{3}$ Perovskite. Nat. Mater. 2018, 17, 1013-1019.

(58) Sharma, P.; Ryu, S.; Burton, J. D.; Paudel, T. R.; Bark, C. W.; Huang, Z.; Ariando; Tsymbal, E. Y.; Catalan, G.; Eom, C. B.; Gruverman, A. Mechanical Tuning of $\mathrm{LaAlO}_{3} / \mathrm{SrTiO}_{3}$ Interface Conductivity. Nano Lett. 2015, 15, 3547-3551.

(59) Sharma, P.; Ryu, S.; Viskadourakis, Z.; Paudel, T. R.; Lee, H.; Panagopoulos, C.; Tsymbal, E. Y.; Eom, C.-B.; Gruverman, A. Electromechanics of Ferroelectric-Like Behavior of $\mathrm{LaAlO}_{3}$ Thin Films. Adv. Funct. Mater. 2015, 25, 6538-6544.

(60) Fan, Z.; Xiao, J.; Sun, K.; Chen, L.; Hu, Y.; Ouyang, J.; Ong, K. P.; Zeng, K.; Wang, J. Ferroelectricity of $\mathrm{CH}_{3} \mathrm{NH}_{3} \mathrm{PbI}_{3}$ Perovskite. J. Phys. Chem. Lett. 2015, 6, 1155-1161.

(61) G, S.; Mahale, P.; Kore, B. P.; Mukherjee, S.; Pavan, M. S.; De, C.; Ghara, S.; Sundaresan, A.; Pandey, A.; Row, T. N. G.; Sharma, D. D. Is $\mathrm{CH}_{3} \mathrm{NH}_{3} \mathrm{PbI}_{3}$ Polar? J. Phys. Chem. Lett. 2016, 7, 2412-2419.

(62) Shao, Y.; Xiao, Z.; Bi, C.; Yuan, Y.; Huang, J. Origin and Elimination of Photocurrent Hysteresis by Fullerene Passivation in $\mathrm{CH}_{3} \mathrm{NH}_{3} \mathrm{PbI}_{3}$ Planar Heterojunction Solar Cells. Nat. Commun. 2014, 5,5784 .

(63) Frost, J. M.; Butler, K. T.; Brivio, F.; Hendon, C. H.; van Schilfgaarde, M.; Walsh, A. Atomistic Origins of High-Performance in Hybrid Halide Perovskite Solar Cells. Nano Lett. 2014, 14, 25842590.

(64) Yuan, Y.; Huang, J. Ion Migration in Organometal Trihalide Perovskite and Its Impact on Photovoltaic Efficiency and Stability. Acc. Chem. Res. 2016, 49, 286-293.

(65) Anaraki, E. H.; Kermanpur, A.; Steier, L.; Domanski, K.; Matsui, T.; Tress, W.; Saliba, M.; Abate, A.; Grätzel, M.; Hagfeldt, A.; Correa-Baena, J.-P. Highly Efficient and Stable Planar Perovskite Solar Cells by Solution-Processed Tin Oxide. Energy Environ. Sci. 2016, 9, 3128-3134. 